\title{
The ISO 14001 environmental management system, a lever for performance and competitiveness of the Moroccan industrial company
}

\author{
Sarra Gazoulit ${ }^{1^{*}}$, Khadija Oubal ${ }^{1}$ \\ ${ }^{1}$ Research Laboratory in Economic Competitiveness and Managerial Performance, CIRPEC, UM5R, 10000, Rabat, Morocco
}

\begin{abstract}
For some years now, Moroccan industrial companies have begun to integrate the environment into their management and to set up an environmental management system, in compliance with international standards, in order to meet the requirements of stakeholders. The fact remains that this management tool has enabled companies to control the impact of their activity on the environment by promoting manufacturing excellence. On a sample of twenty-two large industrial companies with a response rate of $55 \%$, we conducted a quantitative and qualitative study, which allowed us to show the importance of EMS iso 14001 on the performance and competitiveness of the Moroccan industrial company.
\end{abstract}

\section{Introduction}

Since the industrial revolution and until the 1960s, nature was perceived as an inexhaustible source of resources, which led to their exploitation at a higher rate than their renewal [1]. This overexploitation results, among other things, in liquid, solid and atmospheric discharges, thus generating several environmental impacts. These impacts have raised awareness of the need to preserve nature and resources. This awareness has concretely translated into pressure from various sources (clients, associations, the State, etc.), exerted on companies to preserve the natural environment. The protection of the environment has become a sensitive issue for companies, which must be taken into account not only for regulatory reasons but also because of its commercial and financial implications [2]. Not taking care of it amounts to taking serious risks for the future of the company. Today, environmental issues are a strategic issue for many companies, particularly in industry. Taking the environment into account is now part of company management in the same way as production, human resources, purchasing or marketing. Environmental management is based on management tools such as the plant environmental profile (PEP) and the environmental management system (EMS). The most common tool used by companies is the environmental management system, which is described in the ISO 14001 standard. The ISO 14001 EMS is a management tool that allows the company to organize itself in order to reduce and control its environmental impacts [3]. The implementation of the iso 14001 EMS as well as its improvement stimulates a certain number of actions (for example: to acquire anti-pollution techniques, to innovate...) which allow the company to achieve environmental performance and to improve its competitiveness. It is therefore important to study the impact of the EMS, which complies with the international standard, on the performance and competitiveness of the Moroccan industrial company that owns it. To do so, our problem is established as follows: What are the main actions carried out by the Moroccan industrial company within the framework of the implementation and the improvement of the EMS ISO 14001? Do these actions allow the company to achieve environmental performance?

The answers to these questions will allow us to show the impact of the environmental management system, which complies with international standards, on the performance and competitiveness of the Moroccan industrial company that owns it. To answer our problem, we based ourselves on a quantitative and qualitative study carried out on a sample of twenty-two Moroccan industrial companies.

The field of research is made up of both iso 14001 certified establishments - insofar as this certification guarantees the existence of an EMS - and establishments not yet certified iso 14001 but having an EMS in conformity with the international standard. In this article, we will begin by presenting the results relating to companies' motivations for adopting EMS, the main environmental investments made, show the percentage of companies that have benefited from the support of government authorities and those that have made partnerships with NGOs, and then present the impact of the actions carried out by the companies in the sample on environmental performance.

\section{The EMS: Definition \& objectives}

The environmental management system is a management tool that enables the company to organize itself in such a way as to reduce and control its impact on the environment [3]. The EMS has the following objectives: *Identify, assess and prevent environmental risks; *Identify gaps, production or management processes; *Define possible alternatives to improve environmental performance [4].

*Corresponding author: sarra.gazoulit@gmail.com 


\section{Motivations of the companies in the sample}

The companies in the sample were encouraged to integrate the environment into their management, primarily to "become socially responsible" (38\%) and to "comply with regulations" (34\%). In Morocco, there are laws relating to the environment, for example Law No. 11-03 and Law No. 12-03 [5]. Other motivations reported by interviewees are as follows: To meet customer requirements -- especially from abroad -(17\%); to have a competitive advantage (7\%); and to become a leader in environmental matters (3\%).

\section{Environmental investments of the companies of the sample}

The implementation of the environmental policy will require the company to make internal adjustments in the production units or specific installations to recycle or recover part of the waste generated during the production process [6].

$70 \%$ of the companies interviewed dispose of their own end-of-pipe technology (bag filters, treatment plants, oil separators, air treatment plants, chemical treatment plants), as well as specific facilities for recycling waste and wastewater (waste recycling plants, wastewater recycling plants).

$0 \%$ of the companies asked have, in addition to curative technology and specific installations, renewable energy technologies (wind technology), which is the case for cement manufacturers.

Only $10 \%$ of the companies use additive technologies EOP (Electro-Osmotic-Pulse) techniques (Fig. 1).

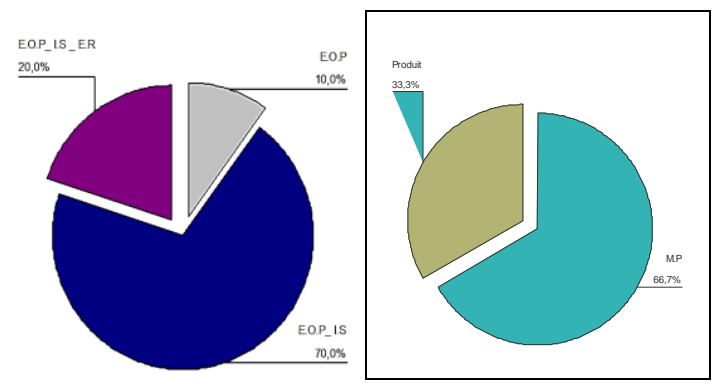

Fig. 1. Technology Investments.

Accordingly, we find that the environmental management system, which is in conformity with the international standard, allows the companies in the sample to optimize their technical resources, not only in its implementation but also in its improvement. It is important to mention that, through the use of environmental technologies and training, the Moroccan industrial company will be able to adopt good environmental practices and achieve their environmental objectives.

\section{Support from government organization (GO) and non-government organization (NGO)}

Half of the companies interviewed $(50 \%)$ receive assistance from regulatory authorities in their approach to environmental protection. $50 \%$ of these companies receive technical assistance from the Moroccan Center of Clean Production (CMPP) [7]. The CMPP is the result of a public-private partnership between the Ministry of Environment on the one hand, and the General Confederation of Moroccan Enterprises on the other hand [7]. 30\% receive financial assistance from the industrial remediation funds (FODEP). FODEP is the result of cooperation between the Department of the Environment and the German Financial Cooperation Agency (KfW). $10 \%$ benefit from the round tables organized by the CMPP [7]. The remaining companies benefit from a reduction in the frequency of regulatory inspections. 58\% of the companies interviewed are in partnership with non-governmental organizations, for example: World Wildlife Fund (WWF), Mohammed VI Foundation for Environmental Protection, to benefit from their expertise in the field of environmental protection, as well as to develop their policies, their own practices and even their own products. Thus, this partnership allows the company to gain agility and sustainability.

\section{EMS: Opportunity to learn from innovation}

The implementation of an EMS is an opportunity for the production of new knowledge and learning [8]. We join the observation of Campinos and Marquette about quality approaches. The drafting of procedures, operating manuals and environmental analysis are collective and produce "cross-learning". The development of the company's skills should enable it to establish itself as a player capable of carrying out innovative actions [9]. Innovation can be of two kinds: Process innovation and product innovation. *Innovation in processes, allows the company to modify its production process. The company can discover new ways to reduce pollution and at the same time increase its level of production because pollution is a sign of inefficiency in the use of resources, raw materials and energy [1]. * Product innovation or ecodesign is a global approach focused on the product. In principle, it consists of taking environmental criteria into account right from the product design phase. These criteria generally concern all phases of a product's life cycle, i.e. production, distribution, use and end of life.

Eco-design is an approach of prevention and reduction at the source of pollution in the respective fields of the companies creating the product. Eco-design is a product design approach that should enable the company to minimize its environmental impacts throughout its life cycle, in a process of continuous improvement and controlled cost [9]. As far as our sample is concerned, the majority of the companies surveyed $(83 \%)$ say that 
the EMS has encouraged them to innovate. $33 \%$ of these companies carry out eco-design, i.e. innovation centered on the product, while $67 \%$ of these companies carry out innovation centered on the means of production or manufacturing processes. Innovation has been stimulated thanks to skills developed in the environmental field. The skills were developed, above all, through strategic partnerships between companies and environmental NGOs (Fig. 2).

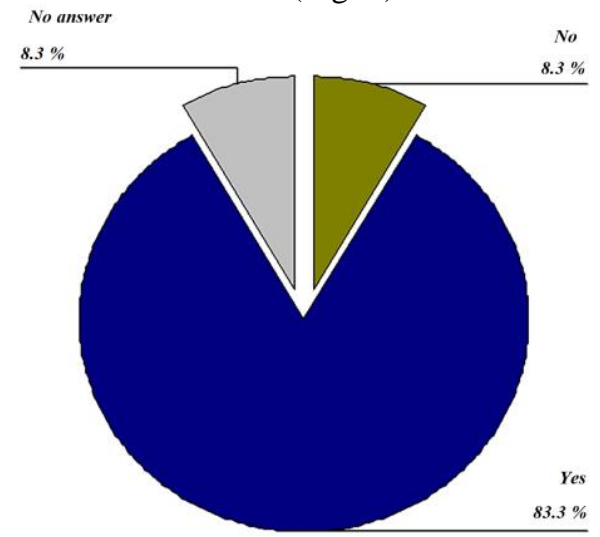

Fig. 2. Innovation in the sampled companies.

\section{Environmental performance of the sample}

Environmental performance is seen as a consequence of manufacturing excellence [10]. 23\% of the companies interviewed have been able to reduce the amount of waste produced over the last three years. We also note that $23 \%$ of the companies surveyed have become more rational in their use of natural resources (water) and that $21 \%$ have succeeded in preserving energy resources. It remains for us to point out that $34 \%$ of those interviewed have achieved a decrease, in the last three years, in $\mathrm{CO}_{2}$ emissions and also in dust emissions. These show the manufacturing excellence of the Moroccan industrial company (Fig. 3).

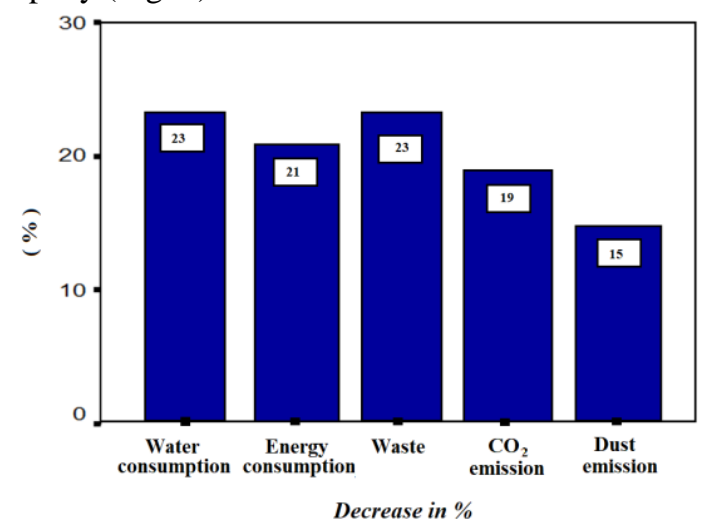

Fig. 3. The environmental performance.

For water consumption: For the last three years, the majority of the companies we interviewed have been able to reduce their water consumption. $40 \%$ of them have achieved a $35 \%$ reduction in water consumption, compared with a $15 \%$ reduction for the rest of the companies (Fig. 3). Indeed, the decrease in water consumption is the result of a number of changes in staff behavior and technology. This decrease is the result of the company' manufacturing excellence. "According to LAFARGE MOROCCO's environmental manager, the reduction in water consumption is due to an effort at the process level: Lafarge Morocco has switched from wet/semi-wet to dry process technology".

For energy consumption: $21 \%$ of the companies surveyed realized a decrease in energy consumption over the last three years. $63 \%$ of these companies realized a decrease of $15 \%$, while $25 \%$ of companies realized a decrease of $35 \%$. The rest of the companies achieved a decrease of $10 \%$ (Fig. 3). Indeed, these results show the effort of this Moroccan industrial firm's effort in process innovation. For waste: Recycling waste into secondary raw materials or alternative fuels enabled $23 \%$ of the companies in the sample to achieve a substantial reduction in the amount of waste produced: a reduction that varies between 11 and 35\% (Fig. 3). It is important to note that waste recovery will also allow these companies to save raw materials and natural resources (gas, coal, etc.). "Doing something for the environment also means saving money for the company and being more competitive" (Director of the CMPP) [7]. Good environmental practices also enabled the majority of the interviewees to lower the cost of wastage (water, energy, waste, etc.), improve their productivity and turnover.

\section{Conclusion}

The study carried out allowed us that the environmental management system (EMS) adopted by the companies in the sample is based on the principles of continuous improvement and prevention, helped them become socially responsible and comply with the regulations in force. Thus, good environmental practices have enabled the companies to make investments (training, technological facilities), to partner with GOs and NGOs in order to achieve manufacturing excellence and environmental performance.

\section{References}

1. A. turki, XII ème conférence de l'Association Internationale de management stratégique. (2003)

2. J. Breau-Triadis, ISO 14001 quoi de neuf après ISO 9000. Qualitique n 106 / Mars, 49 (1999)

3. R. Michaud, école supérieure des géomètres et topographes. (2004)

4. V. Barriat, Guide pratique pour les représentants des travailleurs, Bruxelles, 8 (2003)

5. A. Eddouieb, D.E.S.A en gestion des politiques publiques à la faculté d'Agdal, 29 (2006)

6. B. Bürgenmeier et al,, Economica, Paris, 278 (1997)

7. Centre Marocain de production propres, CMPP News, rapport d'activité (2004)

8. T. Reverdy, Revue française de gestion, (2005).

9. T. Reverdy, Sociologie Pratiques. (2005)

10. L. Moutamalle. L'Harmattan (2004)

11. O. Boiral, Revue française de gestion, (2005) 